\title{
Recruitment of some respiratory muscles during three maximal inspiratory manoeuvres
}

\author{
Stefano Nava, Nicolino Ambrosino, Paola Crotti, Claudio Fracchia, Ciro Rampulla
}

Abstract

Background-A study was undertaken to determine the level of recruitment of the muscles used in the generation of respiratory muscle force, and to ascertain whether maximal diaphragmatic force and maximal inspiratory muscle force need to be measured by separate tests. The level of activity of three inspiratory muscles and one expiratory muscle during three maximal respiratory manoeuvres was studied: (1) maximal inspiration against a closed airway (Muller manoeuvre or maximal inspiratory pressure (MIP)): (2) maximal inspired manoeuvre followed by a maximal expiratory effort (combined manoeuvre); and (3) maximal inspiratory sniff through the nose (sniff manoeuvre). Methods-All the manoeuvres were performed from functional residual capacity. The gastric (PGA) and oesophageal (POES) pressures and their difference, transdiaphragmatic pressure (PDI), and the integrated EMG activity of the diaphragm (EDI), the sternomastoid (EsTR), the intercostal parasternals (ERIC), and the rectus abdominis muscles (ERA) were recorded.

Results-Mean (SD) PDI values for the Muller, combined, and sniff manoeuvres were: $127.6(19.4), 162 \cdot 7(22 \cdot 2)$, and 136.6 $\mathbf{( 2 4 \cdot 8 )} \mathrm{cm} \mathrm{H}_{2} \mathrm{O}$, respectively. The pattern of rib cage muscle recruitment (PoEs/ PDI) was similar for the Muller and sniff manoeuvres $(88 \%$ and $80 \%$ respectively), and was $58 \%$ in the combined manoeuvre, confirming data previously reported in the literature. Peak EDI amplitude was greater during the sniff manoeuvre in all subjects $(100 \%)$ than during the combined $(88 \cdot 1 \%)$ and Muller $(61 \cdot 1 \%)$ manoeuvres. EsTR and EIC were more active in the Muller and the sniff manoeuvres. The contribution of the expiratory muscle (ERA) to the three manoeuvres was $100 \%$ in the combined, $26 \cdot 1 \%$ for the sniff, and $11 \cdot 5 \%$ for the Muller manoeuvre.

Conclusions-Each of these three manoeuvres results in different mechanisms of inspiratory and expiratory muscle activation and the intrathoracic and intra-abdominal pressures generated are a reflection of the interaction between the various muscle groups. The Muller and sniff manoeuvres reflect mainly the force of the inspiratory muscles and the combined manoeuvre that of the diaphragm.

(Thorax 1993;48:702-707)

The measurement of respiratory muscle force is used to evaluate function in conditions such as chronic obstructive pulmonary disease, ${ }^{1-4}$ interstitial lung disease, ${ }^{5}$ and neuromuscular disease.$^{67}$ Maximal transdiaphragmatic pressure (PDImax) is an important index of diaphragmatic strength. ${ }^{8-11}$ Other manoeuvres used to assess respiratory muscle strength include: maximal inspiratory effort against a closed shutter (Muller manoeuvre or the maximal inspiratory pressure $(\mathrm{MIP})){ }^{12}$ a maximal inspiratory manoeuvre combined with a maximal expiratory effort (combined manoeuvre) as described by Laporta and Grassino, ${ }^{10}$ and a sniff through the nose (PDI sniff). ${ }^{13}$ The pressures generated by these manoeuvres depend on the age and sex of the subjects, ${ }^{512}$ the lung volume at which they are performed, ${ }^{14-16}$ and the velocity of shortening of the muscles. The relationship between the force generated by the diaphragm and the other respiratory muscles and the measured pressures may change with different manoeuvres given the complex deformations of the thorax and abdomen resulting from specific recruitment patterns of the respiratory muscles. The force contribution of the different muscles to each of the manoeuvres and their activity during the different efforts has not been fully investigated. Indeed the relative contribution of the diaphragm or other muscles to the genesis of PDI sniff-a manoeuvre recently proposed as a simple and reproducible method-is not known.

The aim of the present study was to investigate the partitioning of pressures between the rib cage and the abdomen, and the patterns of relative activity of three inspiratory muscles (diaphragm, sternomastoid, and intercostals) and one expiratory muscle (rectus abdominis) during the three most commonly used manoeuvres to assess respiratory muscle strength.

\section{Methods}

Nine normal subjects were studied after having obtained informed consent as stated by the Ethical Committee of our Institution. Their mean (SD) age was $37.6(4 \cdot 5)$ years and their static and dynamic lung volumes, 
measured by body plethysmography (Jaeger GmbH, Wurzburg, Germany), were normal. None of the subjects (all practising physicians) had previous experience in performing maximal respiratory efforts nor were they aware of the aims of the study. Oesophageal (POES) and gastric (PGA) pressures were measured using two thin walled balloons, each containing $0.8 \mathrm{ml}$ of air, positioned in the middle third of the oesophagus and in the stomach respectively ${ }^{17}$ and connected by catheters to two differential pressure transducers (Microswitch, Honeywell, $\pm 150 \mathrm{~cm}$ $\mathrm{H}_{2} \mathrm{O}$, Freeport, Illinois, USA). This allowed PDI to be computed by subtraction of PGA from PoEs. The electromyogram (EMG) of the diaphragm (EDI) was obtained in six subjects with both oesophageal and surface electrodes, while in the remaining three it was recorded only with surface electrodes. A Swan-Ganz pacing catheter with a tip mounted balloon was used as an oesophageal electrode; it was inserted into the stomach, inflated, and subsequently anchored at the gastro-oesophageal junction when a good and reproducible signal to noise ratio was obtained during maximal inspiration with the airway occluded. The surface EMG was recorded by electrocardiographic electrodes applied to the skin over the sixth and seventh intercostal spaces close to the upper rib edge. The EMG of the sternomastoid (ESTR) was obtained with surface electrodes positioned over the midpoint of the anterior belly of the right hand muscle, while the intercostal muscle EMG (EIC) was recorded with surface electrodes placed on the second right intercostal space close to the sternum. The EMG of the rectus abdominis (ERA) was obtained from two surface electrodes placed on the anterolateral abdominal wall below the umbilical line after having checked that minimal inspiratory electrical activity was present during spontaneous breathing. All the EMGs were filtered $(0.02-10 \mathrm{kHz}$ bandpass), full wave rectified, and then integrated by a Pynter filter with a time constant of 0.03 seconds.

\section{STUDY DESIGN}

All subjects were studied seated in a comfortable chair with their hands on the arm rest. The same posture of the thorax and neck was maintained throughout the experiment. All the manoeuvres were performed at functional residual capacity assessed from the resting end expiratory oesophageal pressure traces visualised on the chart recorder. For each set of measurements the subject performed a minimum of five manoeuvres, with at least one minute between each effort, until two maximal pressure values were obtained which did not differ by more than 5\%; the higher of the two was chosen for analysis. The subjects were verbally encouraged by the operators to achieve maximal effort. The reproducibility of the manoeuvres with time was assessed by repeating the experiment in three of the subjects a week after the first set of measurements.
The following manoeuvres were performed in random order with a resting period of 15 minutes between.

\section{Sniff manoeuvre}

The subjects were asked to sniff maximally and quickly (less than one second) through the nose with the mouth closed without using a noseclip.

Maximal inspiratory effort (Muller manoeuvre) The volunteers were asked to suck vigorously against a closed airway while breathing through a non-collapsible mouthpiece and wearing a noseclip. A small hole $1.5 \mathrm{~mm}$ in diameter in the mouthpiece prevented closure of the glottis, thus avoiding pressure generation by the cheeks. All manoeuvres were discarded which had been performed incorrectly-that is, plateau pressure not maintained for more than 1.5 seconds or sharp peaks in pressure.

\section{Combined manoeuvre}

The subjects were first instructed to simultaneously perform a Muller manoeuvre through the mouthpiece and then add an expiratory manoeuvre; PGA and PoEs were displayed at the bottom and top of an oscilloscope respectively with the traces moving towards each other. The subjects were then asked to make a maximal effort. PDI was calculated as the sum of the POES and PGA at isotime. Only pressure values obtained with well coordinated manoeuvres were retained for data analysis.

\section{DATA ANALYSIS}

All the EMGs but one (usually EsTR), the PGA and POEs were continuously recorded on a five channel chart recorder (Battaglia and Rangoni, Casalecchio di Reno, Italy). PDI, obtained as electrical subtraction from PGA and POEs by a pressure transducer, was displayed on a storage oscilloscope (Battaglia and Rangoni, Casalecchio di Reno, Italy) during sniff and Muller manoeuvres, while during the combined manoeuvre POES and PGA were visualised simultaneously. All the integrated EMGs, PoES, and PGA, were also recorded in DC mode on a seven channel FM magnetic tape recorder (Racal Recorders Ltd 7DS, Southampton, UK). All the data recorded by tape were then played back and analysed by an AT computer with an A/D board. The pressures were analysed by measuring their peak amplitude from the immediately preceding baseline, while the integrated EMGs were measured as millimetre deflections from baseline and then expressed as a percentage of the maximum reached in the three manoeuvres (fig 1). Since motion artefact or spikes in the EMG signals could affect the amplitude especially during a short sharp effort such as the sniff PDI, we only analysed those EMG signals in which a plateau was seen. In the three subjects who repeated the tests on different days, reproducibility was estimated by comparing the coefficient of variation between PDI, 


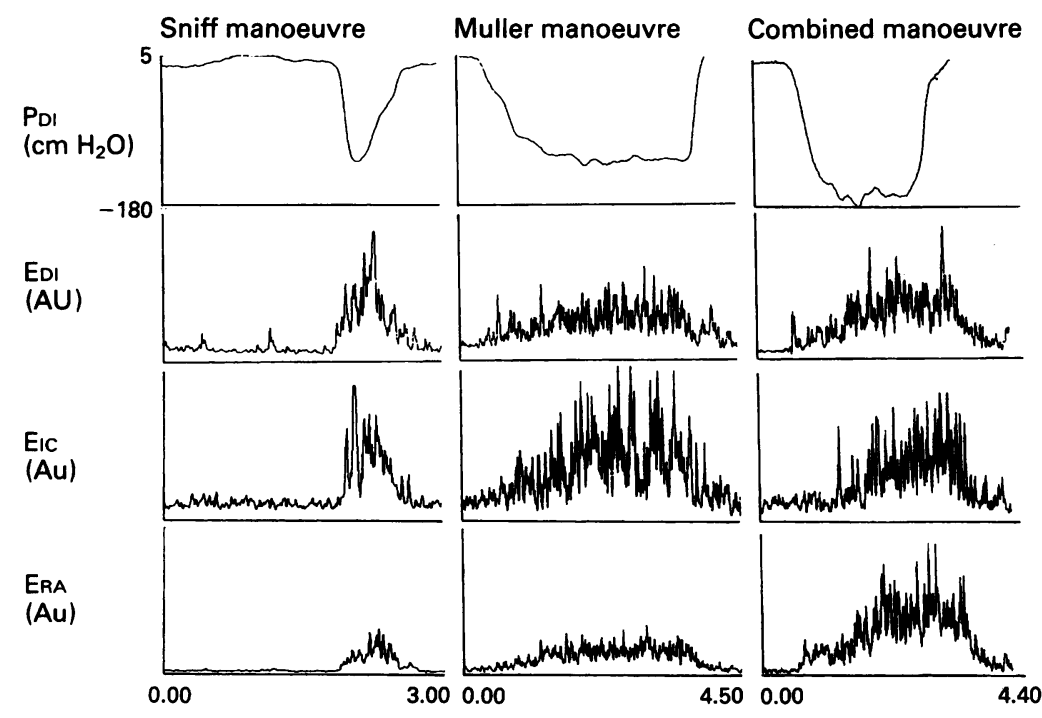

Figure 1 Typical traces of a subject during the three maximal inspiratory manoeuvres. Transdiaphragmatic pressure (PDI) is expressed in $\mathrm{cm} \mathrm{H}_{2} \mathrm{O}$, while the three integrated EMGs (diaphragm (EDI), intercostals (EIC) and rectus abdominis (ERA)) are measured in arbitrary units $(A U)$ as millimetre deflections from the baseline and then expressed as a percentage of the maximum reached in the three manoeuvres.

PoEs, PGA, and the EMGs obtained for each manoeuvre.

All calculated values are presented as means (SD). A paired $t$ test was used, a $\mathrm{p}$ value of $<0.05$ being considered significant.

\section{Results}

Repeatability of the pressure measurements was assessed in three of the subjects on two separate occasions. The results are summarised in table 1 . Whichever manoeuvre was tested, the EMG of the muscles under study always preceded pressure generation.

\section{PRESSURE RESPONSE}

Figure 2 shows the relative contribution of POES and PGA for all the manoeuvres, while table 2 summarises the mean values achieved during the three manoeuvres. The combined manoeuvre produced the highest PDI while the Muller and the sniff manoeuvres gave lower values. The PoEs during the combined manoeuvre was less negative than during the other two manoeuvres. The most positive PGA value was obtained with the combined manoeuvre, with the sniff giving intermediate results ( $p<0.01$ PDI combined $v$ PDI sniff) and the Muller the lowest $(p<0.001$ PDI combined $v$ PDI Muller). Two of the subjects

Table 1 Coefficients of variation (\%) for each of the manoeuvres

\begin{tabular}{llll}
\hline & $\begin{array}{l}\text { Sniff } \\
\text { manoeuvre }\end{array}$ & $\begin{array}{l}\text { Muller } \\
\text { manoeuvre }\end{array}$ & $\begin{array}{l}\text { Combined } \\
\text { manoeuvre }\end{array}$ \\
\hline POES & 1.1 & 1.4 & 3.6 \\
PGA & 4.8 & 1.6 & 4.4 \\
EDI & 0.9 & 1.5 & 1.3 \\
EIC & 1.5 & 1.0 & 2.0 \\
ESTR & 1.8 & 2.3 & 2.7 \\
ERA & 4.1 & 1.1 & 4.9
\end{tabular}

POES-oesophageal pressure; PGA-gastric pressure; EDIintegrated EMG of the diaphragm; EIC-integrated EMG of the intercostal muscles; ESTR - integrated EMG of the sternomastoid; ERA-integrated EMG of the rectus abdominis.

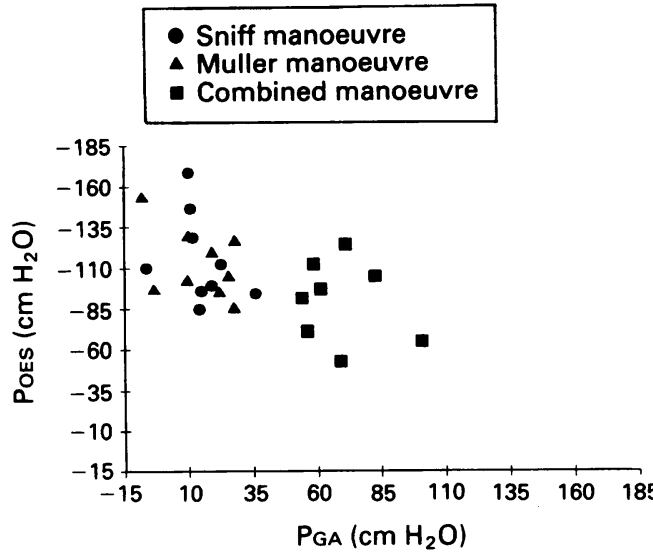

Figure 2 Individual oesophageal (POES) and gastric (PGA) pressures for Muller, combined and sniff manoeuvres.

had a negative PGA during the Muller manoeuvre and one during the sniff.

The pattern of relative chest wall muscle recruitment is expressed by the ratio of POES to PDI; the POES/PDI relationship was $\mathbf{8 8 \%}$ for the Muller manoeuvre, $80 \%$ for the sniff, and $58 \%$ for the combined manoeuvre.

ELECTROMYOGRAPHIC RESPONSE

The integrated electrical activity of the muscles was expressed as a percentage of the manoeuvre that produced the highest activity because it was difficult to compare values obtained during respiratory manoeuvres with those recorded during standardised efforts to determine maximum EMG-that is, closed glottis expulsive manoeuvre for rectus abdominis, isometric contraction against resistance for the sternomastoid-in which the respiratory muscles are working in a totally different way. Figure 3A shows the amplitude of EDI during the three maximal efforts. EDI was greatest in all subjects during the sniff manoeuvre, and only $88 \cdot 1 \%(7 \cdot 3 \%)$ ( $p<$ $0.01)$ and $61.1 \%(14.7 \%)(p<0.001)$ of this value was recorded during the combined and the Muller manoeuvres respectively. As shown in fig $3 \mathrm{~B}$ the combined manoeuvre produced the greatest ERA amplitude, but it was only $26.1 \%(11.5 \%)(p<0.001)$ and $11.5 \%(11.3 \%)(p<0.001)$ of this value during the sniff and Muller manoeuvres. No significant difference was found in the amplitude of EIC and ESTR during the three manoeuvres; less activity in EIC was observed, however, during the combined manoeuvre (fig 4).

The reproducibility of the value of EDI recorded by surface or by oesophageal electrodes was studied in six of the subjects.

Table 2 Mean (SD) maximal pressure ( $\mathrm{cm} \mathrm{H}_{2} \mathrm{O}$ ) according to manoeuvre used

\begin{tabular}{|c|c|c|c|}
\hline Pressure & $\begin{array}{l}\text { Muller } \\
\text { manoeuvre }\end{array}$ & $\begin{array}{l}\text { Sniff } \\
\text { manoeuvre }\end{array}$ & $\begin{array}{l}\text { Combined } \\
\text { manoeuvre }\end{array}$ \\
\hline PDI & $127 \cdot 6(19 \cdot 5)$ & $136 \cdot 6(24 \cdot 8)$ & $162 \cdot 7(22 \cdot 2)$ \\
\hline POES & $113.0(21.5)$ & $110 \cdot 4(27 \cdot 5)$ & $96.4(22.9)$ \\
\hline PGA & $14.4(13 \cdot 3)$ & $24 \cdot 7(11 \cdot 3)$ & $64.5(9.2)$ \\
\hline
\end{tabular}

PDI-transdiaphragmatic pressure; POES-oesophageal pressure; PGA-gastric pressure.

.


Figure 3 (A) Mean amplitudes of the EMG of the diaphragm (EDI) in one of the three

manoeuvres, expressed as a percentage of the maximal EDI reached. (B) Mean amplitudes of the EMG of the rectus abdominis (ERA) in the three manoeuvres. The values bined manoeuvres were highest in all subjects. achieved during the com-
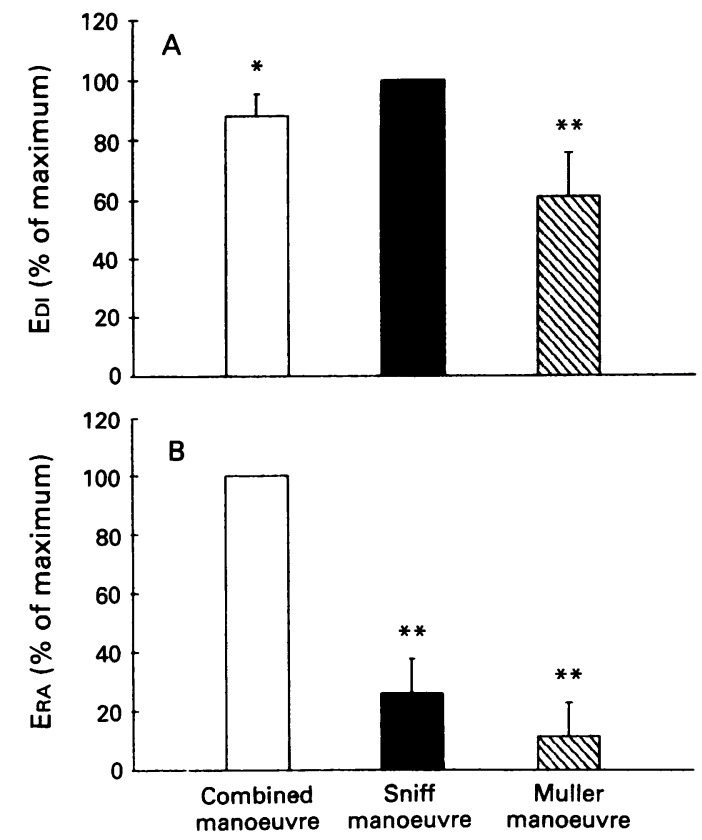

Whichever method was employed, the greater values for EDI were always achieved during the sniff manoeuvre. As illustrated in fig 5 a plot of the difference in EDI between the two recordings from the oesophageal or the surface electrodes showed a trend towards higher values from the surface electrodes during the sniff manoeuvre.

\section{Discussion}

This study has shown that, when untrained normal subjects perform a series of inspiratory manoeuvres, the maximal PDI is achieved during the combined sequence of a maximal inspiratory effort followed by a maximum expiratory effort. The maximal values for POES were measured during the Muller manoeuvre and the sniff test. EMGs of the various inspiratory muscles show that the combined manoeuvre activates the expiratory muscles, which are hardly used in the Muller and sniff manoeuvres; these latter efforts mainly activate the intercostal muscle and the diaphragm. The sternomastoid is also hardly used in these manoeuvres. It therefore seems that maximal transdiaphragmatic pressure (PDImax) and the maximal pressure generat-

Figure 4 Mean amplitudes of the EMG of the sternomastoid (ESTR) and intercostal

parasternals (EIC) in the three manoeuvres expressed as a percentage of the maximal values achieved during the three manoeuvres.

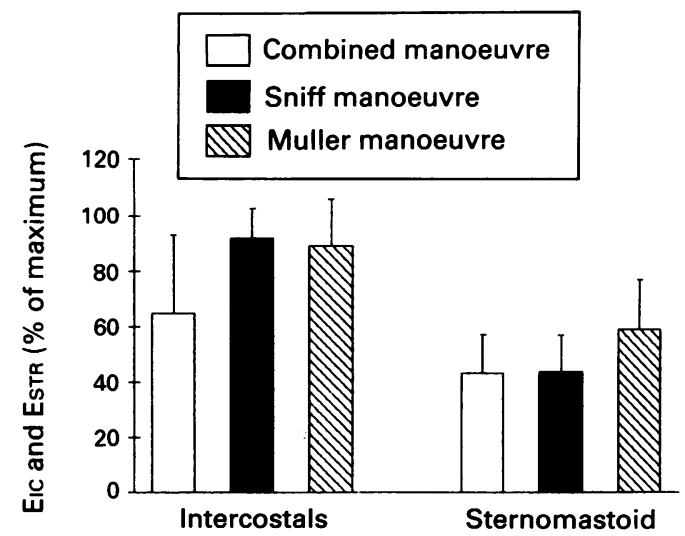

EDI (\% of maximum)

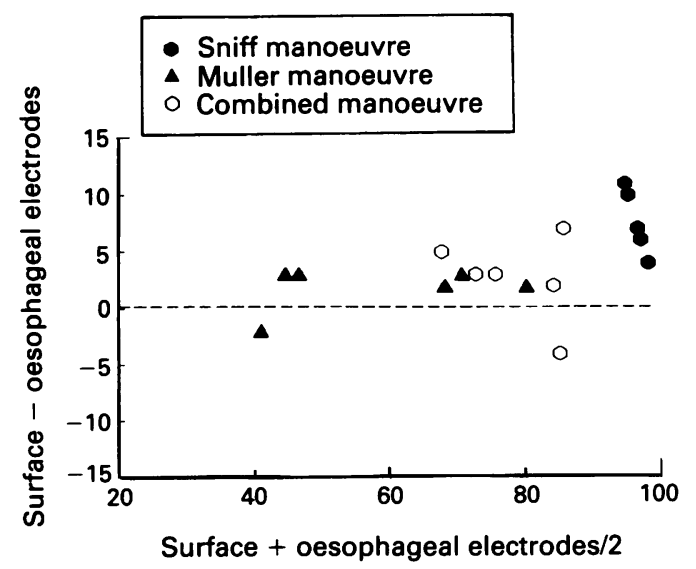

Figure 5 Plot of the difference in EDI between the two methods of recording (surface and oesophageal electrodes) against the mean of the two. Good agreement was found between the two methods.

ed by all the inspiratory muscles (PiMmax) should be measured by separate manoeuvres. These results confirm previous results in trained subjects which showed that the diaphragm is not maximally activated without recruiting the other respiratory muscles, but this contribution was not measured..$^{18}$ Indeed we investigated the relationship between electrical and mechanical activity during PDI sniff, a manoeuvre recently proposed by measuring respiratory muscle strength in clinical practice as it is reproducible and easy to perform. It may also be more useful in detecting weakness in patients who have difficulty in carrying out the Muller or the combined manoeuvres. ${ }^{19} 20$

\section{WHY MEASURE PDImax AND PIMmax?}

Roussos and Macklem ${ }^{21}$ and Bellemare and Grassino $^{22}$ showed that a PDI value $45 \%$ of the PDImax can be maintained indefinitely by subjects breathing against inspiratory resistances. Higher values of PDI will result in the development of fatigue and loss of muscle force. PDImax was then considered as a measure that permitted the assessment of force reserve; this was shown to be true in patients with tetraplegia ${ }^{6}$ as well as in chronic obstructive pulmonary disease. ${ }^{34} \mathrm{~A}$ recent study by Fitting $e t a l^{3}$ showed that breathing against a resistance while voluntarily using the inspiratory muscles of the rib cage rather than the diaphragm resulted in fatigue and failure of the intercostal muscles and sternomastoid while the diaphragm was spared. On the other hand, if the diaphragm and the abdominal muscles were mainly used the diaphragm became fatigued, sparing the intercostal muscles and the sternomastoid. The authors also found that the PDI required to produce fatigue (at a duty cycle of $40 \%$ - that is, ratio of inspiratory time to total respiratory time (TI/TTOT) of 0.4 ) was $45 \%$ of maximum, while the PoEs/PoEsmax was about $70 \%$ of PoEsmax suggesting that PoEsmax obtained independently of the PDImax manoeuvre was higher. Furthermore, a high PGA swing is seldom seen during spontaneous breathing. The present study suggests that the Muller or 
even the sniff test should be the method used to assess the inspiratory muscle force reserve.

PRESSURE AND EMG CHANGES DURING THE THREE MANOEUVRES

The mean value of PDI obtained in the combined manoeuvre appears to be relatively lower than that reported in the literature. ${ }^{102122}$ In contrast to most previous studies, however, our subjects were naive, and it is known that higher values can only be achieved after specific muscle coordination training.

PDI recorded during the combined manoeuvre was higher than during the sniff and Muller tests; this is not surprising as it is the sum of the maximal forces generated by the rib cage and the abdominal compartment. The high activity of the abdominal muscles therefore makes the combined manoeuvre the test of choice to measure diaphragmatic force. As already described by Miller et $a l^{13}$ and Laroche et al, ${ }^{19}$ PDI recorded during the sniff manoeuvre was similar to that achieved during the Muller manoeuvre. Furthermore, these two manoeuvres are similar in terms of relative rib cage muscle recruitment (PoEs/PDI $88 \%$ and $80 \%$, respectively) but not in terms of diaphragm activity. We found that during the Muller manoeuvre the activation of the diaphragm is submaximal compared with activity achieved during PDImax and PDI sniff. Hershenson et al ${ }^{18}$ showed that the application of a negative pressure around the chest increased the value of PDI during the Muller manoeuvre. This may mean that the diaphragm - the "stronger agonist"-is limited in generation of force by the action of the inspiratory rib cage muscles which is the "weaker agonist." This mechanism prevents an important inward distortion of the rib cage.

In the present study we were able to show how the intercostal parasternals are nearly maximally activated during all three manoeuvres in most of the subjects (six of nine) In the three subjects in which the parasternals were less active the ESTR achieved the greater amplitude as this muscle could take over the role of the intercostals in stabilising the rib cage conformation. It may be concluded that PDI measured during the Muller manoeuvre does not maximally activate the diaphragm; while the "weaker agonist" muscles-the intercostal parasternal and sternomastoidsare greatly activated as suggested by Hershenson et al. ${ }^{18}$

\section{LIMITATIONS OF THE STUDY}

Much of this investigation relies on the use of surface electrodes to record the electrical activity of the muscles other than the diaphragm. ${ }^{24-26}$ This method may be criticised because of possible interference by other muscle groups. In recording the EMG of the rectus abdominis during the three maximal manoeuvres we may have picked up some diaphragmatic electrical activity since this muscle moves downwards during inspiration, but this problem cannot be avoided with fine wires or other kinds of similar electrodes. We took great care in placing the surface electrodes below the umbilical line where the contamination from the diaphragm during spontaneous breathing was negligible or nonexistent. The intercostal parasternal muscles are located directly beneath the pectoralis major muscle so the recording of their EMG by surface electrodes is likely to be contaminated. We therefore placed the electrodes in the second intercostal space close to the costal border where little electrical activity of the pectoralis major was observed. The EMG of the diaphragm recorded with the surface electrodes mainly reflects the activity of the costal part, while the oesophageal electrodes mainly measures activity in the crural part. The rather good agreement between the two measurements suggests that the activation of the two diaphragmatic parts is similar in the tests used to measure maximal respiratory muscle strength; surface electrodes may therefore also be used, thus avoiding the introduction of a catheter through the nose.

We conclude that the pressure generated in the three most common manoeuvres used to assess respiratory muscle strength is a reflection of complex interactions between several muscle groups since these efforts produce different mechanisms of activity of inspiratory and expiratory muscles. The three manoeuvres may reasonably be used in clinical practice, knowing that they may have different physiological connotations; the Muller and sniff tests should be used primarily to assess inspiratory muscle reserve, and the combined test to detect that of the diaphragm.

We wish to thank Dr RC Stannert for kindly reviewing the English of the manuscript and Dr Alex Grassino for useful talks and suggestions.

1 Byrd RB, Hyatt RE. Maximal respiratory pressures in chronic obstructive lung disease. Am Rev Respir Dis 1968;98:848-56.

2 Sharp JT, Van Lith P, Vej Nuchprayoon, Briney $R$ Johnson FN. The thorax in chronic obstructive lung disease. Am F Med 1968;44:39-46.

3 Rochester DF, Braun NM, Arora NS. Respiratory muscle strength in chronic obstructive pulmonary disease. $A m$ Rev Respir Dis 1979;119:151-4.

4 Bellemare F, Grassino A. Force reserve of the diaphragm in patients with chronic obstructive pulmonary disease. f Appl Physiol 1983;55:8-15.

5 De Troyer A, Yernault JC. Inspiratory muscle force in normal subjects and patients with interstitial lung disease. Thorax 1980;35:92-100.

6 Gross D, Ladd W, Riley EJ, Macklem PT, Grassino A The effect of training on strength and endurance of the diaphragm in quadriplegia. Am ₹ Med 1980;68:27-35.

7 Estrup C, Lyager S, Olsen C. Effect of respiratory muscle training in patients with neuromuscular diseases and in normals. Respiration 1986;50:36-43.

8 De Troyer A, Estenne M. Limitations of measurement of transdiaphragmatic pressure in detecting diaphragmatic weakness. Thorax 1981;36:169-74.

9 Gibson GJ, Clark E, Pride NB. Static transdiaphragmatic pressures in normal subjects and in patients with chronic hyperinflation. Am Rev Respir Dis 1981;124:685-9.

10 Laporta D, Grassino A. Assessment of transdiaphragmatic pressure in humans. $₹$ Appl Physiol 1985;58:1469-76.

11 Rochester DF, Braun NMT. Determinants of maximal inspiratory pressure in chronic obstructive pulmonary disease. Am Rev Respir Dis 1985;132:42-7.

12 Black LF, Hyatt RE. Maximal respiratory pressures: normal values and relationship to age and sex. Am Rev Respir Dis 1969;9:696-702.

13 Miller JM, Moxham J, Green M. The maximal sniff in the assessment of diaphragm function in man. Clin $\mathrm{Sc}_{\mathrm{i}}$ 
1985;69:91-6.

14 Agostoni E, Rahn H. Abdominal and thoracic pressures at different lung volumes. F Appl Physiol 1960;15:1087-92.

15 Braun NMT, Arora NS, Rochester DF. Force-length relationship of the normal human diaphragm. F Appl Physiol 1982;53:405-12.

16 Wanke T, Schenz G, Zwick H, Popp W, Ritschka L Flicker $M$. Dependence of maximal sniff generated mouth and transdiaphragmatic pressures on lung volume. Thorax 1990;45:352-5.

17 Milic-Emili J, Mead J, Turner JD, Glauser FM Improved technique for studying pleural pressure from esophageal balloons. $f$ Appl Physiol 1964;13:207-11.

18 Hershenson MB, Kikuchi Y, Loring SH. Relative strengths of the chest wall muscles. If Appl Physiol 1988;65:852-62.

19 Laroche CM, Mier AK, Moxham J, Green M. The value of sniff esophageal pressures in the assessment of global inspiratory muscle strength. Am Rev Respir Dis 1988;138:598-603.
20 Mier A, Brophy C, Moxham J, Green M. Assessment of diaphragm weakness. Am Rev Respir Dis 1988;137:877-83.

21 Roussos C, Macklem PT. diaphragmatic fatigue in man. 7 Appl Physiol 1977;43:189-97.

22 Bellemare F, Grassino A. Effect of pressure and timing of contraction on human diaphragm fatigue. $\mathcal{f}$ Appl Physiol 1982;53:1190-5.

23 Fitting JW, Bradley TD, Easton PA, Lincoln MI, Goldman M, Grassino A. Dissociation between diaphragmatic and rib cage muscle fatigue. $\mathcal{F}$ Appl Physiol 1988;64:959-65.

24 Gross D, Grassino A, Ross WRD, Macklem PT. Electromyographic pattern of diaphragmatic fatigue. $\mathfrak{f}$ Appl Physiol 1979;56:1-7.

25 Gallagher CG, Im Hof V, Yornes M. Effects of inspiratory muscle fatigue on breathing pattern. $\mathcal{f}$ Appl Physiol 1985;59:1152-8.

26 Bellemare F, Grassino A. Evaluation of human diaphragm fatigue. F Appl Physiol 1982;53:1196-206.

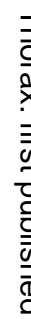

